\title{
Corrigendum
}

\section{Corrigendum to "Growth of premature neonates admitted in a level III neonatal unit” [Clin. Epidemiol. Glob. Health 2 (2) (2014) 56-60]}

\author{
Neha Agarwal ${ }^{\mathrm{a}}$, Mala Kumar ${ }^{\mathrm{b}}$, Shalini Tripathi ${ }^{\mathrm{c}}$, S.N. Singh ${ }^{\mathrm{b}}$ \\ a Resident, Department of Pediatrics, King George's Medical University, Lucknow, Uttar Pradesh, India \\ b Professor, Department of Pediatrics, King George's Medical University, Lucknow, Uttar Pradesh, India \\ c Assistant Professor, Department of Pediatrics, King George's Medical University, Lucknow, Uttar Pradesh, India
}

Background to the change in authorship:

This paper was submitted on 20 September 2013, by:

- Authors: Mala Kumar, Shalini Tripathi, Neha Agarwal, S.N. Singh Department of Pediatrics, King George’s Medical University, Lucknow, Uttar Pradesh, India.

The manuscript was Accepted 21 January 2014. Available online 17 March 2014.

Thereafter Dr. Neha Agarwal, on April 7, 2017, appealed to the journal that this publication was from her post-graduate thesis work under the chief supervisor Prof. Mala Kumar and co-supervisor Prof. S.N. Singh. Dr. Neha Agarwal had formulated the idea of writing research paper from her thesis. However the manuscript was written after she had completed her residency and left the department. The prime mover for thesis writing was her Chief Supervisor, Prof. Mala Kumar. Since this work was from the postgraduate thesis of Dr. Neha Agarwal she claimed to first authorship, which was accepted by the corresponding author Prof. Mala Kumar.

\section{Conclusion}

There was a change in authorship while the paper essentially contained the same information on the same topic as submitted in the first version. It appears that the work was done primarily by Dr. Neha Agarwal under supervision of Prof. Mala Kumar and Prof. S.N. Singh. Dr. Shalini Tripathi assisted in reanalysis, interpretation and manuscript writing in absence of Dr. Neha Agarwal.

The initial list of authorship has not been handled according to the rules of the journal and the COPE (Committee on Publication Ethics) Guidelines, as outlined below: Authors are expected to consider carefully the list and order of authors before submitting their manuscript and provide the definitive list of authors at the time of the original submission. Any addition, deletion or rearrangement of author names in the authorship list should be made only before the manuscript has been accepted and only if approved by the journal Editor. To request such a change, the Editor must receive the following from the corresponding author: (a) the reason for the change in author list and (b) written confirmation (e-mail, letter) from all authors that they agree with the addition, removal or rearrangement. In the case of addition or removal of authors, this includes confirmation from the author being added or removed.

COPE Guidelines state that in case of authorship issues Editors should consider publishing a Corrigendum, and that a Retraction is not considered appropriate if there is no reason to doubt the validity of the findings. 